\title{
Comparison of Eulerian and Lagrangian moisture source diagnostics - the flood event in eastern Europe in May 2010
}

\author{
A. Winschall, S. Pfahl, H. Sodemann, and H. Wernli \\ Institute for Atmospheric and Climate Science, ETH Zurich, Zurich, Switzerland \\ Correspondence to: S. Pfahl (stephan.pfahl@env.ethz.ch)
}

Received: 13 June 2013 - Published in Atmos. Chem. Phys. Discuss.: 8 November 2013

Revised: 14 April 2014 - Accepted: 27 May 2014 - Published: 1 July 2014

\begin{abstract}
Moisture convergence from different sources is an important prerequisite for a heavy-precipitation event. The contributions from different source regions can, however, hardly be quantified from observations, and their assessment based on model results is complex. Two conceptually different numerical methods are widely used for the quantification of moisture sources: Lagrangian approaches based on the analysis of humidity variations along backward trajectories and Eulerian methods based on the implementation of moisture tracers into a numerical model. In this study the moisture sources for a high-impact, heavy-precipitation event that affected eastern Europe in May 2010 are studied with both Eulerian and Lagrangian moisture source diagnostics. The precipitation event was connected to a cyclone that developed over northern Africa, moved over the Mediterranean towards eastern Europe and induced transport of moist air towards the Carpathian Mountains. Heavy precipitation and major flooding occurred in Poland, the Czech Republic and Slovakia between 16 and 18 May 2010. The Lagrangian and Eulerian diagnostics consistently indicate a wide spatial and temporal range of moisture sources contributing to the event. The source with the largest share is local evapotranspiration from the European land surface, followed by moisture from the North Atlantic. Further contributions come from tropical western Africa $\left(10-20^{\circ} \mathrm{N}\right)$ and the Mediterranean Sea. Contrary to what could be expected, the Mediterranean contribution of about $10 \%$ is relatively small. A detailed analysis of exemplary trajectories corroborates the general consistency of the two approaches, and underlines their complementarity. The Lagrangian method allows for mapping out moisture source regions with computational efficiency, whereas the more elaborate Eulerian model requires predefined moisture sources, but includes also processes such as precipita-
\end{abstract}

tion, evaporation and turbulent mixing. However, in the Eulerian model, uncertainty concerning the relative importance of remote versus local moisture sources arises from different options to parameterise moisture tagging at the surface. Ultimately a more sophisticated parameterisation scheme will be required to reduce this uncertainty.

\section{Introduction}

In May 2010 several countries in eastern Europe - especially Poland, the Czech Republic, Hungary and Slovakia - were affected by intense precipitation (Bissolli et al., 2011). Between 15 and 18 May 2010 heavy precipitation occurred in a small area at the border of Poland, the Czech Republic and Slovakia. After this period eastern Europe was affected by further rainfall until early June. This combination of intense precipitation in the beginning with further moderate precipitation during the second half of May and the beginning of June had a huge impact on a large region in eastern Europe. While major cities were spared from large damages due to recent dike building, rural areas suffered from considerable damages due to flooding. There were 15 fatalities in the aftermath of the flood (Bissolli et al., 2011).

In this study we focus on the period of heavy precipitation between 15 and 18 May 2010. This very intense rainfall was connected to a low-pressure system that developed over northern Africa two days before the start of the event. The low-pressure system moved over the Mediterranean towards eastern Europe and transported a moist air mass towards the Carpathian Mountains, which induced orographically enhanced heavy precipitation. Several previous events with a similar synoptic configuration (named $\mathrm{Vb}$ track 
situation after van Bebber, 1891) led to intense flooding in central or eastern Europe. The Oder flood in 1997 (Keil et al., 1999), the Elbe flood in 2002 (Ulbrich et al., 2003a, b; Stohl and James, 2004; Sodemann et al., 2009) and the heavy-precipitation event hitting the northern ridge of the Alps in August 2005 (Appenzeller et al., 2006; Zängl, 2007a, b; Hohenegger et al., 2008) occurred due to a similar synoptic development. The prevalent view on the moisture transport associated with such events, which is also put forward in several of the above-mentioned papers, states that the low-pressure system moving from the Mediterranean towards central or eastern Europe transports moisture from the Mediterranean Sea, which then rains out during the precipitation event. Keil et al. (1999), Stohl and James (2004) and Sodemann et al. (2009) used different techniques in order to explicitly investigate the moisture sources for the respective heavy-precipitation events. Keil et al. (1999) studied the moisture sources for the Oder flood by analysing horizontal fluxes of precipitable water and found that moisture transport from the Mediterranean was important for the event. A Lagrangian method based on forward-trajectory calculations to diagnose the moisture sources for the flood in August 2002 was applied by Stohl and James (2004). They determined the Mediterranean as the major source region, but also mentioned land evapotranspiration as an important factor for the heavy-precipitation event. Sodemann et al. (2009) used a numerical tracer diagnostics (so-called moisture tagging) implemented in the Climate High-Resolute Model (CHRM) to investigate the moisture sources for the 2002 Elbe flood and found a variety of sources (Atlantic, Mediterranean, Black Sea, subtropics) contributing to the event. With the same tagging implementation Winschall et al. (2012) investigated the influence of intense North Atlantic evaporation on a precipitation event in Piedmont in November 2002.

Two classes of diagnostic methods for quantifying the moisture sources for (heavy) precipitation events are widely used. The Eulerian approach applies online numerical moisture tracers implemented in climate (Joussaume et al., 1986; Koster et al., 1986; Bosilovich and Schubert, 2002; Goessling and Reick, 2013) or weather prediction models (Sodemann et al., 2009; Winschall et al., 2012; Sodemann and Stohl, 2013). The Lagrangian approach is based on the analysis of moisture changes along trajectories, either forward trajectories covering the whole domain of interest or backward trajectories initialised at the location of the precipitation event (Dirmeyer and Brubaker, 1999; James et al., 2004; Sodemann et al., 2008; Gimeno et al., 2010; Sodemann and Zubler, 2010). Recently, Goessling and Reick (2013) used Eulerian moisture tracers in a climate model to critically evaluate the well-mixed assumptions made in some Lagrangian diagnostics. A review of Lagrangian and Eulerian methods for diagnosing moisture sources has been presented by Gimeno et al. (2012). The two approaches are conceptually and technically different and associated with specific advantages and weaknesses. The Eulerian approach based on online moisture tracers requires numerical simulations with complex atmospheric circulation models, which are computationally expensive but allow for an explicit representation of many processes relevant for the atmospheric water cycle, such as surface evaporation and turbulent mixing. The Lagrangian approach is based on trajectory calculations using analysis or model output fields and is computationally more efficient. However, important processes such as evaporation and precipitation are only conceptually represented as moisture changes along trajectories.

Validating such source diagnostics is not straightforward as moisture from different sources can hardly be distinguished by measurements. This study explores the methodological uncertainties related to different moisture source diagnostics by comparing the results from a Eulerian tagging implementation in the COSMO weather prediction model (see Sect. 2.1) and a Lagrangian diagnostics following Sodemann et al. (2008) (see Sect. 2.2) for the heavy-precipitation event in eastern Europe in May 2010. A central focus of the study is to quantify the extent to which the results obtained from the two complementary approaches to diagnose evaporative moisture sources agree. This will shed further light on the usefulness and potential weaknesses of the two techniques.

After a technical description of the Eulerian and Lagrangian approaches in Sect. 2, the synoptic situation before and during the heavy-precipitation event is analysed in Sect. 3. The results of the Eulerian and Lagrangian methods are described in Sects. 4 and 5, respectively. Section 6 presents a comparison of these results, which is extended by an analysis of exemplary trajectories in Sect. 7. The paper finishes with conclusions in Sect. 8.

\section{Methods}

\subsection{Eulerian approach}

The Eulerian approach for quantifying moisture sources is based on the concept of moisture tagging. Tracers are introduced into the moisture cycle of a (in this case limitedarea) numerical model labelling moisture from pre-specified sources. These tracers are initialised when moisture enters the model domain via evaporation from the land or ocean surface or transport through the boundaries. On the way to precipitation the moisture tracers experience all processes of the atmospheric water cycle that are explicitly simulated or parameterised in the model, such as advective transport, cloud formation, convection and turbulent mixing. Finally, the contribution of the different tracers (i.e. different moisture sources) to precipitation in a specific target region can be quantified. Note that our tagging implementation only applies to the atmospheric part of the model, and the tracer information is not retained in continental water reservoirs. This means that moisture loses its source tag once it reaches the 
surface in the form of precipitation or through other fluxes (like dew formation).

The moisture tagging has been implemented in the COSMO limited-area model, which is used operationally by the German and Swiss weather services and several other meteorological institutions. It is a limited-area model based on the thermo- and hydro-dynamical equations describing the flow dynamics of the moist atmosphere (Doms and Schättler, 2002; Steppeler et al., 2003). The COSMO model is non-hydrostatic and designed for high-resolution simulations with a horizontal grid spacing of the order of $1 \mathrm{~km}$ (Baldauf et al., 2011). In the horizontal the grid points are distributed on a rotated longitude-latitude grid. In the vertical time-independent terrain-following coordinates are used. For the spatial discretisation second-order finite differences and a staggered Arakawa C-grid are applied. The time integration follows a two-time-level, second-order time-splitting Runge Kutta scheme (Wicker and Skamarock, 1998). In this study a one-moment bulk microphysical scheme with the categories water vapour, cloud water, cloud ice, rain and snow as well as a Tiedtke convection scheme (Tiedtke, 1989) are used. Doms et al. (2005) give detailed information on the parameterisation schemes of the COSMO model.

For the simulation of moisture tracers a secondary water cycle has been introduced in the COSMO model, similar to the implementation of water isotopes by Pfahl et al. (2012). As this method is entirely diagnostic, the secondary moisture cycle does not interact with the primary moisture cycle nor affect any other model component. The moisture tracers (corresponding to different tagged moisture sources) experience all processes in the same way as the standard (total) moisture. If, for instance, the formation of a cloud is simulated, the different tracers composing the total moisture contribute to the cloud formation according to their respective fractions in water vapour (for details, see Sodemann et al., 2009). The fourth-order Bott scheme (Bott, 1989) is used for the advection of total and tagged moisture. The implementation of this scheme has been slightly adapted to improve mass conservation (Winschall, 2013).

The evaporation of moisture from the surface is parameterised following a flux-gradient approach (see Doms et al., 2005):

$F_{\mathrm{sfc}}=-c_{\mathrm{turb}}\left(q_{1}-q_{\mathrm{sfc}}\right)$,

where $F_{\text {sfc }}$ denotes the vertical flux of moisture between the surface and the atmosphere, and $c_{\text {turb }}$ the turbulent diffusion coefficient. $q_{1}$ and $q_{\mathrm{sfc}}$ are the specific humidity at the first COSMO model level and at the surface, respectively. A positive value of $F_{\text {sfc }}$ corresponds to an upward moisture flux (i.e. evaporation), which occurs when the specific humidity at the surface is larger than on the first model level. For the case of dew formation $\left(F_{\mathrm{sfc}}<0\right)$, the surface fluxes of the different moisture tracers are proportional to the total flux and the respective tracer fraction, as for the example of cloud formation described above. For evaporation $\left(F_{\mathrm{sfc}}>0\right)$, there are two ways to adapt the parameterisation to the moisture tracers: One is to use the gradient of total moisture for the evaporation of the tracers (e.g. Koster et al., 1986), the other is to use the moisture gradient of the individual tracers (e.g. Sodemann et al., 2009). Using the total moisture gradient for parameterising tracer evaporation (called "Evap_tot" approach in the following) implies that tagged moisture from the underlying surface can only enter the atmosphere when there is a gradient in total specific humidity between the surface and the first model level. In this case, the evaporation rate of the associated tracer equals the evaporation rate of total moisture:

$F_{\mathrm{sfc}}^{\mathrm{t}}= \begin{cases}F_{\mathrm{sfc}} & \text { for tracer associated with surface area } \\ 0 & \text { otherwise }\end{cases}$

where $F_{\text {sfc }}^{\mathrm{t}}$ denotes the tracer evaporation flux. However, this Evap_tot approach neglects the turbulent mixing of different tracers in the column between the surface and the first model level. If instead the specific humidity gradient of each tracer is taken into account, tracers can mix even though there is no net moisture flux:

$F_{\mathrm{sfc}}^{\mathrm{t}}=-c_{\mathrm{turb}}\left(q_{1}^{\mathrm{t}}-q_{\mathrm{sfc}}^{\mathrm{t}}\right)$.

Here, $q_{1}^{\mathrm{t}}$ and $q_{\mathrm{sfc}}^{\mathrm{t}}$ denote the tracer's specific humidity at the first COSMO model level and at the surface, respectively. The latter is equal to the total surface humidity $q_{\mathrm{sfc}}$ in source regions of the specific tracer and 0 everywhere else. This approach, for which $F_{\text {sfc }}^{\mathrm{t}}$ for every tracer is proportional to its individual moisture gradient, is called "Evap_tag" in the following. In this case, the sum of all tracer fluxes equals the evaporation rate of total moisture. In summary, the Evap_tot approach does not account for mixing of tracers close to the surface nor between atmosphere and surface, while the mixing in the Evap_tag approach is very strong. The Evap_tot approach records where an air parcel is fueled by net evaporation, whereas the Evap_tag approach is closer to mimicking the actual movement of water molecules in the surface layer, for which two-directional turbulent fluxes can be important. The two methods thus provide different information on the source-sink relationship of atmospheric moisture (see also Goessling, 2013).

At the beginning of a tagging simulation, all moisture that is located in the model domain is of unknown source. This initial atmospheric moisture is separately tagged as atmospheric tracer and needs to be removed until the target event is simulated in order to be able to decompose the simulated precipitation into the specified sources. The removal of the atmospheric tracer by precipitation or advection out of the model domain requires time, which is longer for large model domains. However, long forecast lead times degrade the quality of the simulation of the precipitation event. To avoid this problem, we implemented the possibility of exchanging the information on tracer distributions between separate short model runs as illustrated in Fig. 1. This procedure is called 


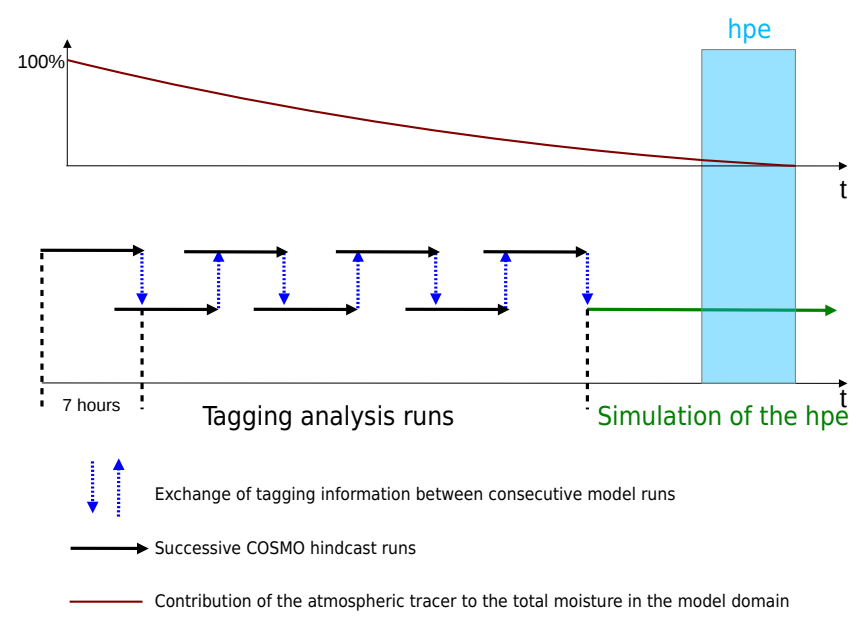

Figure 1. Schematic plot illustrating the concept of tagging analysis. The heavy-precipitation event is denoted by hpe. The atmospheric tracer tags the moisture that is present in the atmosphere at the beginning of the simulation.

tagging analysis, and can be thought of as a simple assimilation scheme of European Centre for Medium-Range Weather Forecasts (ECMWF) analysis data into successive COSMO tagging simulations. It allows producing initial conditions for tagging experiments with a known source composition of the initial moisture in the atmosphere. Before the simulation of the precipitation event, a series of 7-hourly runs overlapping for $1 \mathrm{~h}$ is conducted with the COSMO tagging model. At the end of each run the fractional distribution of the moisture tracers is used for initialising the tracer distribution of the next 7-hourly run. In this way the atmospheric tracer is removed step by step, but the standard meteorological fields do not substantially deviate from the ECMWF analysis, which is used to supply initial and boundary conditions for each 7hourly run and the final simulation of the heavy-precipitation event. Note that at the time of initialisation of each 7-hourly run the total moisture distributions of the two COSMO runs do not match exactly. This may lead to some minor inconsistencies. For instance, if a cloud is present in the newly initialised run, but not in the simulation from which the tracer distribution is carried over, the relative tracer composition of water vapour has to be used for initialising the cloud water. Nevertheless, since the simulations are short, we assume that these inconsistencies do not substantially affect the final tracer distribution.

\subsection{Lagrangian approach}

The Lagrangian method to quantify the moisture sources for a heavy-precipitation event follows the implementation introduced by Sodemann et al. (2008). It is based on studying short-term changes of specific humidity along backward trajectories from the location of the heavy-precipitation event. Assuming that humidity changes in an air parcel are de- termined by the difference of evaporation and precipitation (James et al., 2004), a positive moisture change (a so-called moisture uptake) results from evaporation exceeding precipitation, and a negative moisture change from precipitation exceeding evaporation. The impact of a moisture uptake along a trajectory on the precipitation in the target region depends on the intermediate moisture changes between the considered uptake and the precipitation in the last time step. A strong uptake shortly before the precipitation event has a high contribution, while the contribution of an equally strong moisture uptake some days before the event might be lower because of intermediate loss of moisture due to precipitation. If the air parcel is located in the atmospheric boundary layer $(\mathrm{ABL})$, an uptake can be directly attributed to evaporation from the underlying source region, as the boundary layer is considered to be well mixed. Uptakes in the free troposphere, above the ABL, may be connected to unresolved processes like horizontal or vertical mixing. A scaled boundary layer height of 1.5 times the parameterised boundary layer height of the COSMO model is used here to account for uncertainties in the ABL parameterisation and temporal variations in the ABL height. The source contributions from different backward trajectories are weighted according to their contributions to the total precipitation, which is estimated based on the moisture decrease during the last trajectory time step. More detailed technical information on the Lagrangian moisture diagnostic is given in Sodemann et al. (2008).

\section{Synoptic situation}

Figure 2 illustrates the synoptic situation at 14, 15 and 16 May 2010, which are the two days before and the day of the precipitation maximum, based on ECMWF analysis data. At 00:00 UTC on 14 May 2010 a large upper-level trough expanded from western Europe to Morocco (Fig. 2a). The trough induced a flow of warm air at its forefront, leading to a baroclinic zone over Algeria just ahead of the trough. In this region a surface low-pressure system developed during 13 May (Fig. 2b), which might also be affected by lee cyclogenesis in the vicinity of the Atlas Mountains. Figure $2 b$ also displays the specific humidity at $850 \mathrm{hPa}$ and shows an accumulation of moisture north and east of the developing low-pressure system. Furthermore, values of increased humidity are visible over eastern Europe, which might contribute to the precipitation on the following days. One day later at 00:00 UTC on 15 May 2010 the trough axis was located over the western Mediterranean (Fig. 2c). The lowpressure system had intensified and moved over the Mediterranean. A very moist air mass was located east of the cyclone centre with specific humidity values of more than $10 \mathrm{~g} \mathrm{~kg}^{-1}$ at $850 \mathrm{hPa}$ (Fig. 2d). High values of moisture were also present at other levels of the troposphere, leading to a maximum in vertically integrated precipitable water in this region (not shown). During 15 May the surface low moved towards 
$\Theta$ and wind @ 850 hPa, PV@ $330 \mathrm{~K}$

(a)

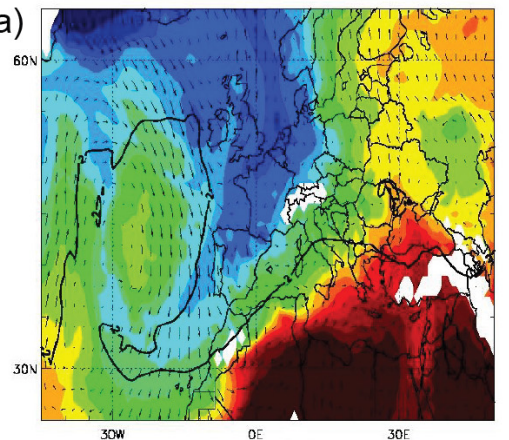

14 May 2010, 00 UTC q, Z, and wind @850 hPa

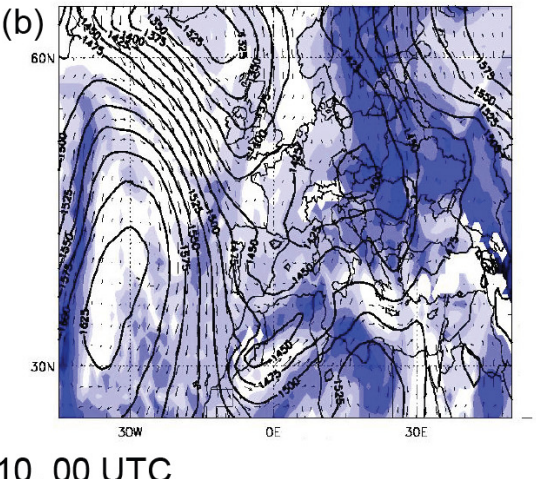

(c)



(d)

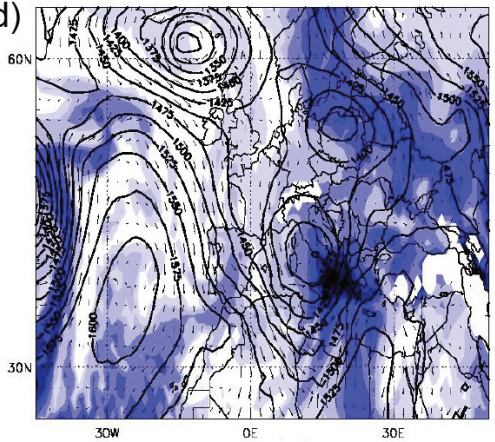

15 May 2010, 00 UTC

(e)

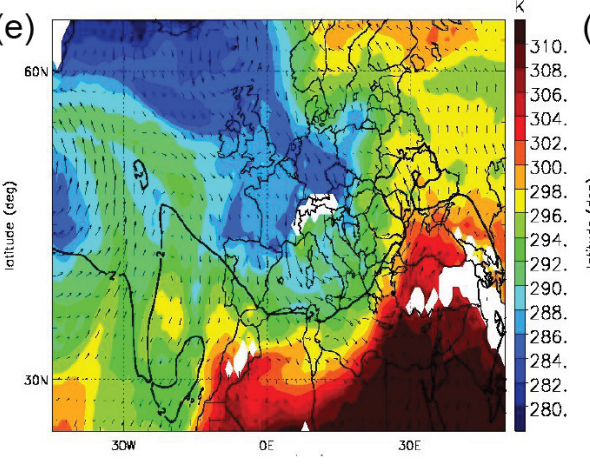

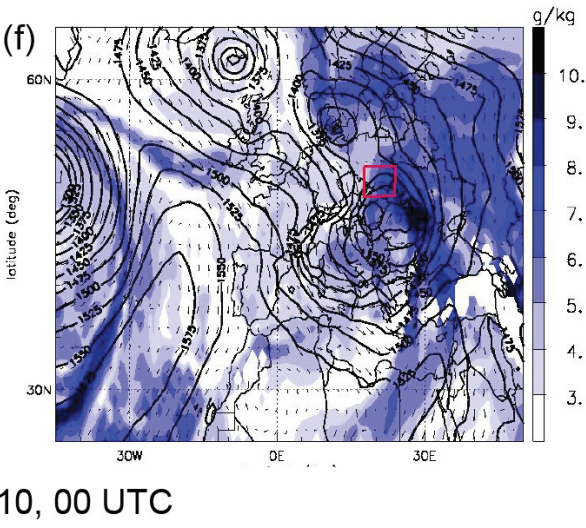

Figure 2. Left panels: ECMWF operational analysis of potential temperature (shading, in $\mathrm{K}$ ), wind arrows at $850 \mathrm{hPa}$ and potential vorticity at $330 \mathrm{~K}$ ( 2 pvu contour) at 00:00 UTC on (a) 14, (c) 15 and (e) 16 May 2010. Right panels: ECMWF operational analysis of specific humidity (shading, in $\mathrm{g} \mathrm{kg}^{-1}$ ), geopotential height and wind arrows at $850 \mathrm{hPa}$ at 00:00 UTC on (b) 14, (d) 15 and (f) 16 May 2010. The red box in (f) marks the target region of the tagging experiment and the Lagrangian moisture diagnostic.

eastern Europe and induced a flow of moist air towards the ridge of the Carpathian Mountains, which led to orographically induced precipitation that lasted from the evening of 15 May to early 18 May with peak values on 16 May. The accumulated precipitation between 00:00 UTC on 15 May and 00:00 UTC on 18 May 2010 is plotted in Fig. 3a, showing gridded station measurements from the ENSEMBLES daily gridded observational dataset (E-OBS) (Haylock et al., 2008). The precipitation shows a maximum at the border of Poland, Slovakia and the Czech Republic. Values exceed $150 \mathrm{~mm}$ in this area, while in a broader area north of the Carpathian ridge precipitation values of 70 to $90 \mathrm{~mm}$ were measured over a 3-day period. At 00:00 UTC on 16 May 2010 the broad upper-level trough covered large parts of the Mediterranean and the low-pressure system, which was still located ahead of the trough, was fully developed (Fig. 2e and f). In accordance with the high precipitation values during 
(a)

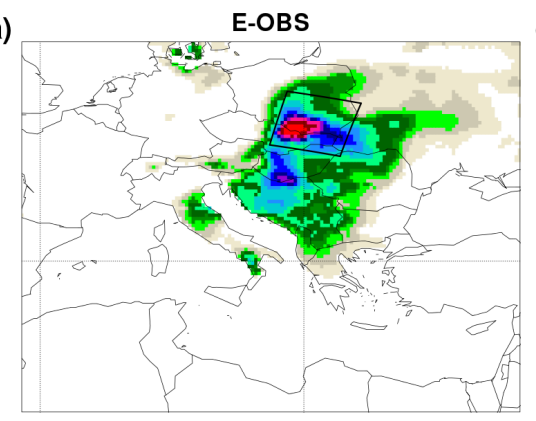

(b)

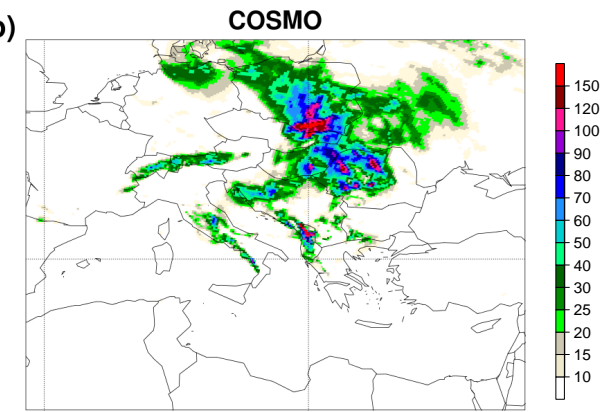

Figure 3. (a) Observed (E-OBS data set; Haylock et al., 2008) and (b) simulated (COSMO) 72-hourly accumulated precipitation in mm between 00:00 UTC on 15 May and 00:00 UTC on 18 May 2010. The black frame in (a) shows the target region.

16 May, high values of specific humidity over eastern Europe can be found in Fig. 2f.

Based on this synoptic analysis, different potential moisture contributions to the precipitation event are likely important: moisture from northern Africa, where the low-pressure system developed; a possible moisture enhancement during the movement over the Mediterranean; and high specific humidity values present in eastern Europe already before the low-pressure system arrived. This qualitative view on moisture transport and convergence, however, does not provide information on the relative contributions of different sources. In the following sections we aim to quantify the impact of the above-mentioned and possibly additional moisture sources on the intense precipitation event with the help of Eulerian and Lagrangian diagnostics.

\section{Numerical simulation and tagging results}

For the simulation of the precipitation event the COSMO model has been run with a horizontal resolution of $0.125^{\circ}$ (about $14 \mathrm{~km}$ ), 40 vertical levels and a simulation period of 144 h from 00:00 UTC on 13 May 2010 to 00:00 UTC on 19 May 2010. The simulation has been initialised and driven at the boundaries with operational ECMWF analysis data. The outer frame in Fig. 4a shows the model domain, which is large enough to cover most of the possible moisture sources that may contribute to the event. It extends almost to the Equator in the south and covers about half of the North Atlantic in the west. The small box over eastern Europe denotes the target region where the intense precipitation occurred. The results from the tagging simulation are evaluated with respect to this box, and the backward trajectories for the Lagrangian moisture quantification in Sect. 5 are started from this target region.

For the tagging experiment the total moisture in the model domain has been split into 9 different sources as shown in Fig. 4. Moisture from the North Atlantic is split into a northern part (Atl_n), which also covers moisture that is advected through the north-western model boundaries, and a southern subtropical/tropical part (Atl_s) including moisture enter- ing the domain through the south-western model boundaries. Moisture evaporating from the Mediterranean Sea is tagged with a separate tracer (Med), and the evapotranspiration from land surfaces in the model domain is split into three different tracers: evapotranspiration from the African land surface (Lnd_afr), and tracers for the European (Lnd_eur) as well as for the Middle East and Russian (Lnd_mea) land surfaces. Land evapotranspiration from additional land surfaces in the domain (e.g. Greenland) has been separately tagged but is not discussed further as its contribution to the considered event is negligible. Further tracers are moisture evaporating from the Black Sea and parts of the Caspian Sea and entering through the north-eastern boundaries (Bls), and (sub-)tropical moisture evaporating from the Red Sea and entering through the south-eastern model boundaries(Tro). Finally the tracer Atm tags all moisture that is present in the model domain at the beginning of the simulation. The large model domain would require a long forecast lead time to remove the Atm tracer within one model run. We therefore apply the tagging analysis technique (see Sect. 2.1) with successive 7-hourly runs starting at 00:00 UTC on 20 April 2010. In these successive runs from 20 April to 13 May the Atm tracer is removed so that the main run can be initialised with a known distribution of the eight other tracers and a well-defined initial analysis state. Note that the tagging results presented in this section are based on the Evap_tot parameterisation (see Sect. 2.1). In Sect. 6 additional results from the Evap_tag parameterisation will be presented for comparison.

Figure $3 \mathrm{~b}$ shows the precipitation simulated by the COSMO model accumulated from 00:00 UTC on 15 May to 00:00 UTC on 18 May 2010. The simulated precipitation is in good agreement with the observations of heavy precipitation in the target region (see again Fig. 3a). The location of the precipitation maximum is slightly shifted towards the east, and a band of high precipitation values is simulated north of the maximum that was not observed. Some of the mismatches (e.g. over the Carpathian Mountains) may also be due to incomplete observational coverage. In general the simulated precipitation pattern is acceptable considering the relatively coarse resolution of $14 \mathrm{~km}$ and the large 

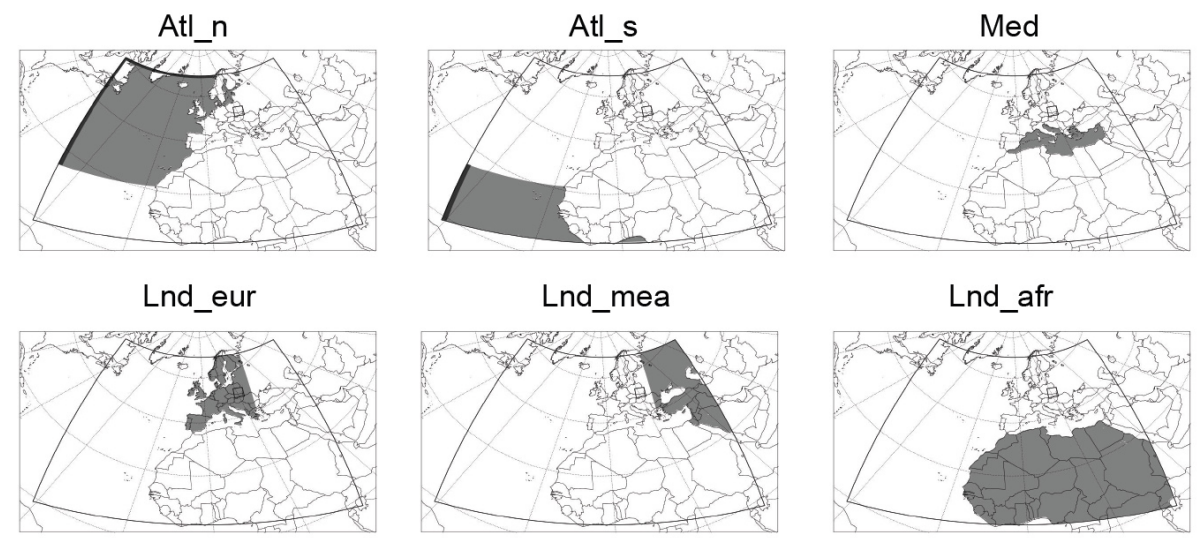

Bls
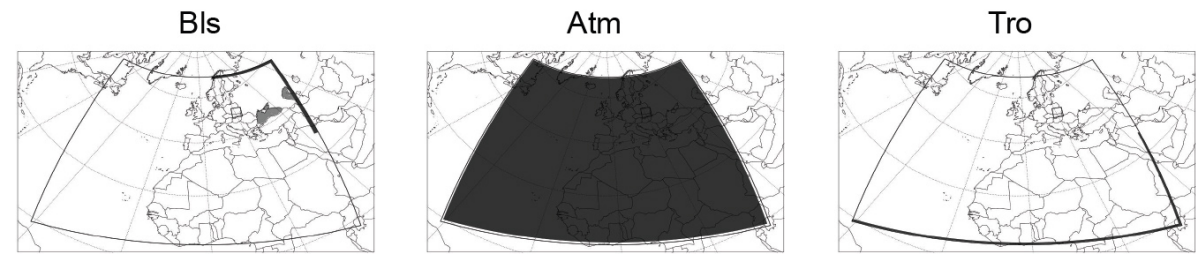

Figure 4. Initialisation set-up of the tagging tracers for the case study of the May 2010 flood event. Light-grey shaded areas show surfaces where evaporating water is tagged. Water tagged within an atmospheric box is shown by dark-grey shading. The small black frame indicates the target region in eastern Europe that was affected by the heavy-precipitation event. The large outer frame corresponds to the model domain.

model domain. The spatial average of the 72-hourly accumulated precipitation over the target region amounts to $55.5 \mathrm{~mm}$ in the COSMO simulation and $61.0 \mathrm{~mm}$ in the E-OBS data set. In comparison to ECMWF analyses, the simulated wind, sea level pressure and humidity structure at 00:00 UTC on 16 May 2010 (beginning of the precipitation event) is properly simulated by the COSMO model (not shown). The location and intensity of the low-pressure system and the high values of moisture east of the low are very similar in the COSMO run compared to the analysis, indicating a correct simulation of the large-scale dynamics and moisture transport. Altogether, the COSMO model is able to reasonably reproduce the heavy-precipitation event in eastern Europe in May 2010, which is necessary for a meaningful interpretation of the tagging results.

The hourly precipitation averaged over the target region in eastern Europe (specified in Fig. 3a) is plotted in Fig. 5. The thick black line indicates the total simulated precipitation. The main amount of precipitation is simulated between 12:00 UTC on 15 May and 00:00 UTC on 18 May, in agreement with observations (Bissolli et al., 2011). Precipitation continues until 12:00 UTC on 19 May. With the tagging technique this total precipitation can be decomposed into different sources, as shown by the colour shading. A variety of different sources contribute to the precipitation in the target region. The two largest sources are moisture from the North Atlantic (Atl_n) and local evaporation from the European land surface (Lnd_eur), with total contributions of 37 and $27 \%$, respectively (see Table 1). Additionally, moisture from the Middle East (Lnd_mea), the Mediterranean and the south-
Table 1. Relative contributions of the different moisture sources to the precipitation in the target region between 00:00 UTC on 15 May and 00:00 UTC on 18 May 2010 (in \%). The first column shows results from the COSMO tagging simulation with parameterisation Evap_tot, the second column from the simulation with parameterisation Evap_tag and the third column from the Lagrangian diagnostics.

\begin{tabular}{lrrr}
\hline & Evap_tot & Evap_tag & Lagr. \\
\hline Atm & 3 & 1 & 6 \\
Med & 11 & 5 & 13 \\
Lnd_mea & 7 & 14 & 16 \\
Lnd_eur & 27 & 65 & 43 \\
Lnd_afr & 7 & 8 & 4 \\
Tro & 7 & 3 & 0 \\
Atl_s & 1 & 0 & 0 \\
Atl_n & 37 & 9 & 14 \\
Bls & 2 & 0 & 4 \\
\hline
\end{tabular}

ern sources Lnd_afr and Tro contributes between 7 and $11 \%$ each. Contributions from the sources Bls and Atl_s are negligible. Hence a combination of regional evapotranspiration and a convergence of remote moisture from the Atlantic and from tropical regions constitutes the majority of the moisture supply for the precipitation event, while moisture from the Mediterranean only has a fraction of about $10 \%$. Note however that the vertical distribution of the moisture is important for the generation of precipitation, and the Mediterranean 


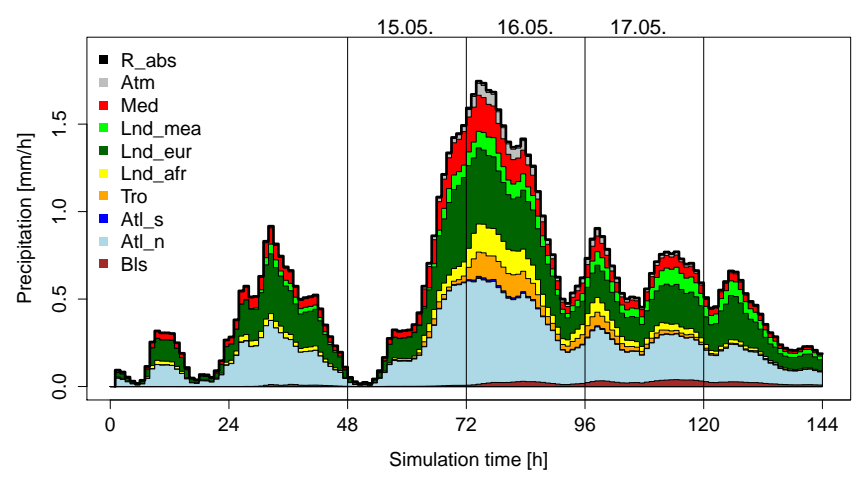

Figure 5. Time series of hourly precipitation (in $\mathrm{mm}$ ) from individual moisture sources (shading) in the target region in eastern Europe (see Fig. 3a).

moisture might contribute considerably to the near-surface moistening of the atmosphere.

Figure 6 shows the horizontal distribution of the vertically integrated water vapour from the six most important moisture sources at 12:00 UTC on 16 May 2010, i.e. close in time to the precipitation peak in the target area. Moisture from the two southerly sources Tro and Lnd_afr is transported within an extended band from a local maximum over western Africa (around $15^{\circ} \mathrm{N}$ ) over the Sahara towards the Mediterranean and, together with the developing low-pressure system, to eastern Europe (Fig. 6a and b). Particularly the strong northward excursion to $60^{\circ} \mathrm{N}$ of the Lnd_afr tracer is notable. The moisture evaporating from the European land masses converges locally in the region of the precipitation event (Fig. 6c and d). Mediterranean moisture is transported with the lowpressure system towards eastern Europe in a cyclonic path (Fig. 6f). The weak evaporation from the Mediterranean during the simulation period is reflected in relatively low values of precipitable water of the Med tracer. Moisture from the North Atlantic is uniformly distributed over the western part of the model domain, including central and eastern Europe (Fig. 6e).

To further illustrate the transport path of moisture from southerly sources (Tro and Lnd_afr tracer) three-dimensional kinematic backward trajectories have been calculated from a region covering the target domain shown in Figs. $3 \mathrm{a}$ and 4 (longitudes between 20 and $30^{\circ} \mathrm{E}$, latitudes between 45 and $55^{\circ} \mathrm{N}$ ) based on ECMWF analysis data. The trajectories were started at 12:00 UTC on 16 May 2010 from a horizontal grid of $1^{\circ} \times 1^{\circ}$ and vertical levels between 950 and $500 \mathrm{hPa}$ in steps of $50 \mathrm{hPa}$. Figure $7 \mathrm{a}$ shows the selection of trajectories with a northward movement of at least $30^{\circ}$ during the calculation time of $168 \mathrm{~h}$. Five \% of the trajectories fulfil this criterion, mostly started from the central part of the domain and from levels above $800 \mathrm{hPa}$. As shown in Fig. 7a, the air parcels move from western Africa around $10^{\circ} \mathrm{N}$ towards eastern Europe within 9 days. The trajectories are coloured with specific humidity, showing a moistening of up to $10 \mathrm{~g} \mathrm{~kg}^{-1}$ in a region around $15^{\circ} \mathrm{N}, 10^{\circ} \mathrm{W}$. The black dots mark the positions of the air parcels over western Africa at 00:00 UTC on 10 May 2010. As the air parcels are located in the mid-troposphere at this point (not shown) the moistening is not directly connected to surface evaporation. It might instead be related to an African easterly wave system, which developed during 10 May 2010 near the location of the air parcels over western Africa, as shown in the infrared satellite image in Fig. 7b. African easterly waves are organised, westward-moving systems of intense convection that form over tropical Africa. The vertical moisture transport due to this convection may have led to the moisture increase along the trajectories (see again Fig. 7a). The subsequent advection of this tropical moisture towards Europe indicated by the trajectories is also diagnosed as a specific tropical moisture export event by the objective Lagrangian analysis performed by Knippertz et al. (2013).

In summary, the tagging experiment shows that both local moisture recycling through evapotranspiration from land surfaces and long-range transport from the North Atlantic and western Africa constitute important moisture sources for the precipitation falling during the heavy rainfall event in eastern Europe in May 2010. In the following, the robustness of these results with respect to the applied methodology is assessed through a comparison with a Lagrangian source diagnostic.

\section{Results of the Lagrangian analysis}

For the application of the Lagrangian moisture source diagnostics, three-dimensional kinematic backward trajectories have been calculated based on wind and humidity fields from the COSMO simulations analysed in Sect. 4, starting from the same target region as defined for the tagging study. Every $6 \mathrm{~h}$ between 00:00 UTC on 15 May and 00:00 UTC on 18 May 2010 backward trajectories were started from about 8700 starting points covering the entire target region (see Fig. 3a) on a regular grid with $25 \times 25 \mathrm{~km}$ grid spacing in the horizontal and on vertical levels from 1000 to $550 \mathrm{hPa}$ in steps of $30 \mathrm{hPa}$ (which implies that each trajectory represents the same total mass). The trajectories have been calculated backwards to 20 April 2010 to be consistent with the setup of the Eulerian tagging experiment. For the period from 20 April to 13 May input data were taken from the tagging analysis simulations (see Sect. 2.1). Note that this might lead to small inconsistencies because of discontinuities in the wind and humidity fields. By analysing moisture changes along the trajectories, the source regions of the precipitating water have been determined (see Sect. 2.2).

Figure 8a shows a map of the moisture uptakes within the ABL identified by the Lagrangian diagnostics. These uptakes can be linked directly to moisture evaporating from the surface below, as the boundary layer is considered to be well mixed. Moisture uptakes in air parcels located in the free troposphere are plotted in Fig. 8b. Positive moisture changes 

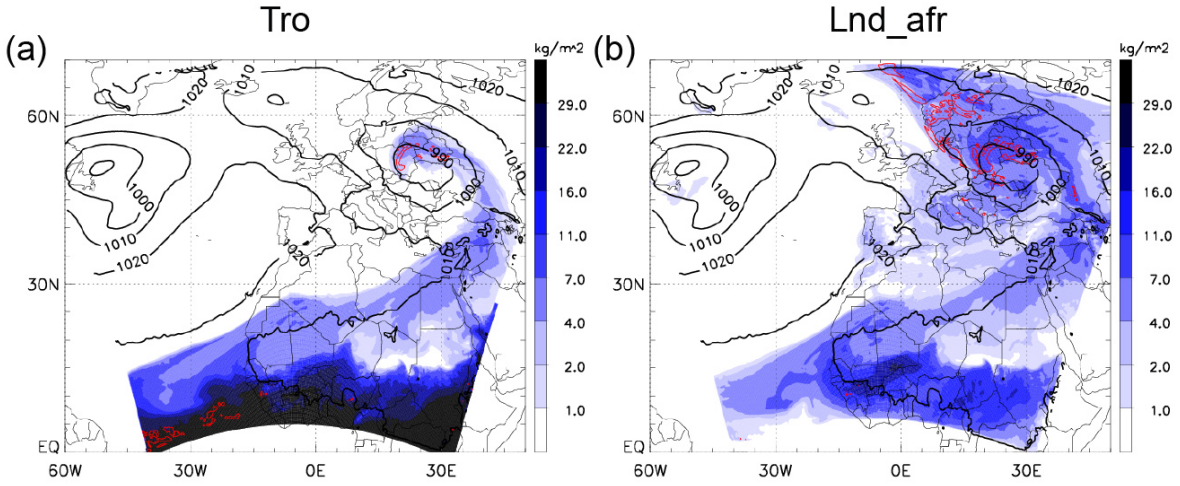

(c)

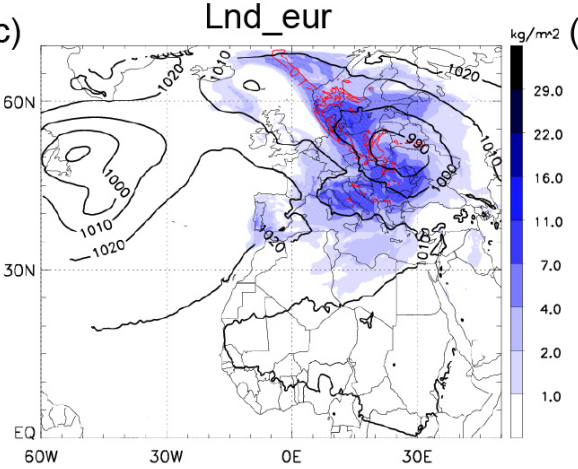

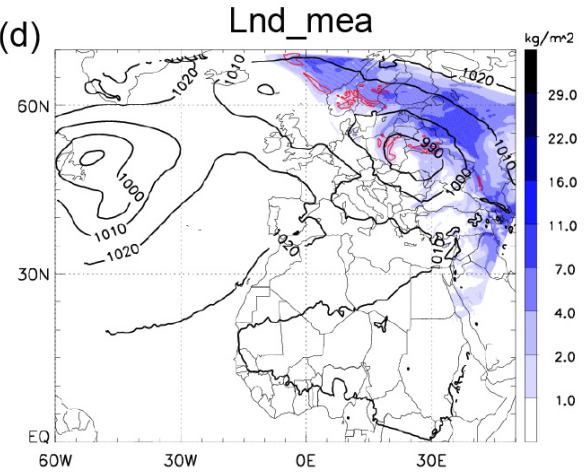

Med
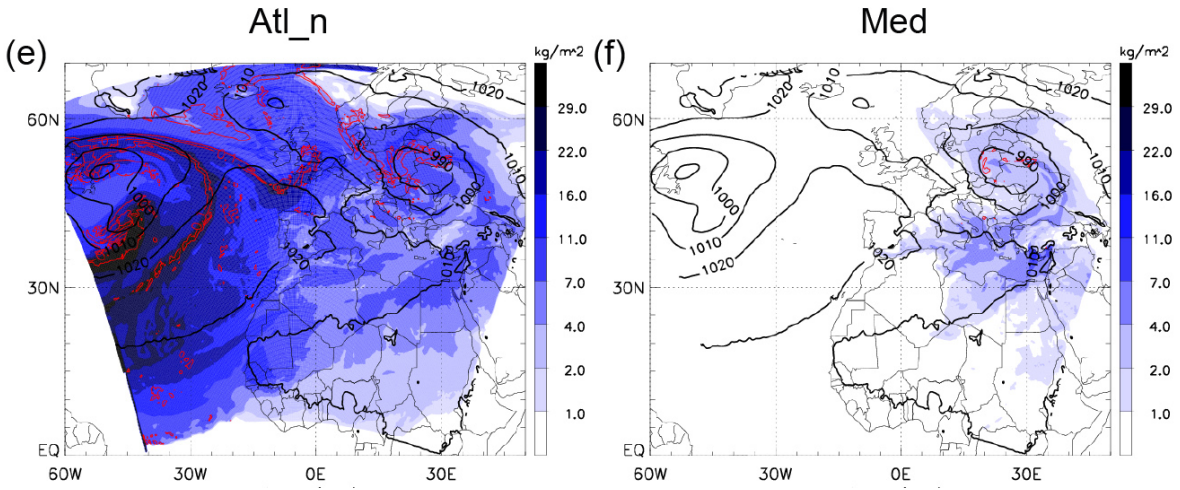

Figure 6. Vertically integrated tagged water vapour $\left(\mathrm{kg} \mathrm{m}^{-2}\right.$, blue shading) and vertically integrated tagged cloud water (red contour of $0.1 \mathrm{~kg} \mathrm{~m}^{-2}$ ) from sources (a) Tro, (b) Lnd_afr, (c) Lnd_eur, (d) Lnd_mea, (e) Atl_n and (f) Med and sea level pressure (black contours every $10 \mathrm{hPa}$ ) at 12:00 UTC on 16 May 2010.

above the boundary layer can be connected to convection, turbulent mixing processes or to errors and inconsistencies in the trajectory calculation. For these free tropospheric uptakes the direct link of the uptake location and surface evaporation is thus less straightforward. However, the spatial patterns of $\mathrm{ABL}$ and free tropospheric moisture uptakes are similar (Fig. 8a and b). They show a distinct maximum of comparable magnitude in the region of the event in eastern Europe. Furthermore, two main branches of moisture transport can be identified: a south-westerly branch with moisture uptakes over south-western Europe, the Mediterranean, North Africa and the North Atlantic, as well as a north-westerly branch with uptakes over central and northern Europe and the north- ern North Atlantic. The north-westerly branch is mainly associated with precipitation forming at relatively low altitudes (below $3000 \mathrm{~m}$ ), whereas the southerly sources contribute more to the precipitation forming further aloft (not shown). A small signal over Africa between 0 and $20^{\circ} \mathrm{N}$ is found in the free tropospheric uptakes, which corresponds to the influence of the Tro and Lnd_afr tracers found in the Eulerian tagging study and the discussion at the end of Sect. 4. The moisture of trajectories entering through the model boundaries is also diagnosed as moisture uptake, analogously to the boundary boxes of the tagging setup that mark the moisture entering the model domain. In Fig. $8 \mathrm{~b}$ this leads to free tropospheric moisture uptake signals at the domain boundaries 

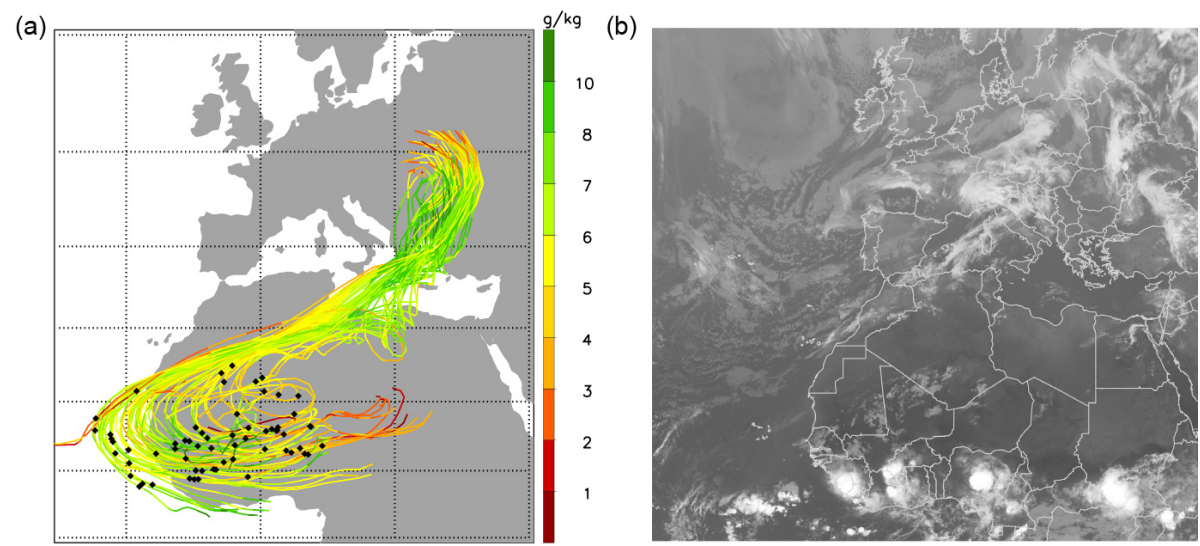

Figure 7. Left panel: $168 \mathrm{~h}$ backward trajectories from the region of the precipitation event, started at 12:00 UTC on 16 May 2010, with the condition of at least $30^{\circ}$ northward movement during the calculation time (only every second trajectory is shown). The black dots mark the position of the air parcel at 00:00 UTC on 10 May 2010. Right panel: EUMETSAT infrared image at 00:00 UTC on 10 May 2010. The white colours in the tropics indicate convective cloud systems.

(a)

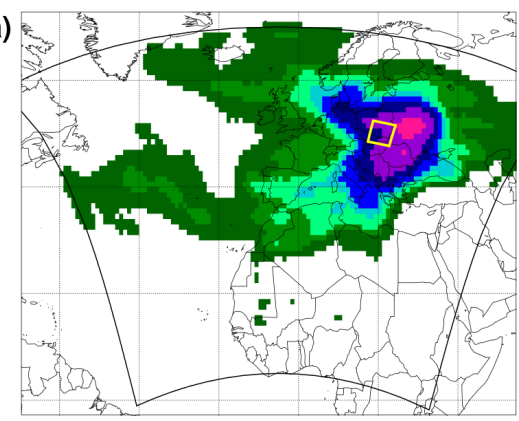

(b)

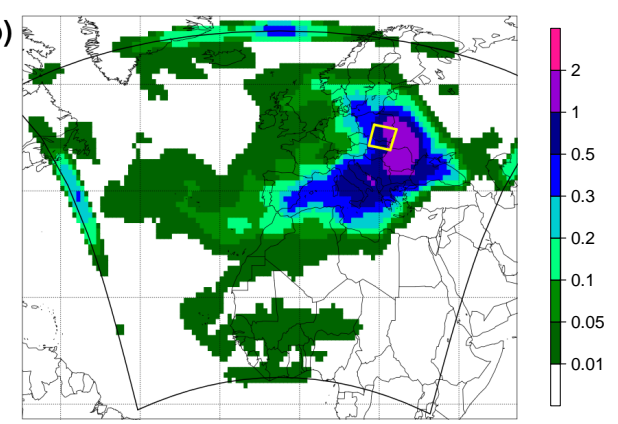

Figure 8. Moisture sources for the May 2010 precipitation event identified with the Lagrangian approach. The maps show moisture uptakes (in units of $\mathrm{mm}(72 \mathrm{~h})^{-1}$ ) for the precipitation in the target region specified in Fig. 3a accumulated from 00:00 UTC on 15 May to 00:00 UTC on 18 May 2010. (a) shows moisture uptakes within the ABL; (b) shows the free tropospheric uptakes. The black frame in both panels indicates the model domain of the COSMO simulation; the yellow box shows the target region. Note the non-linear scale.

east of Greenland, south of Newfoundland and over tropical Africa. As the results are very similar for moisture uptakes within the ABL and in the free troposphere, the sum of all uptakes is used in the following quantitative comparison.

\section{Comparison of the Eulerian and Lagrangian approaches}

In this section we compare the results of the Eulerian tagging approach and the Lagrangian diagnostics. While the Eulerian method is based on a simulation with a numerical model, which includes a detailed representation of all relevant processes of the atmospheric moisture cycle (evaporation, microphysics, etc.), in the Lagrangian approach these processes are only conceptually represented by moisture changes along trajectories. A quantitative comparison shows whether the two methods yield consistent estimates of the moisture sources contributing to the heavy-precipitation event. Moreover, the sensitivity of the Eulerian approach with respect to the parameterisation of tracer surface evaporation is explored in this section by including results from the Evap_tag parameterisation in the comparison.

To directly compare the moisture source estimates from the different diagnostics, each moisture uptake from the Lagrangian approach (Fig. 8) was assigned to the corresponding source region specified in the tagging setup (see Fig. 4). The uptakes diagnosed at the domain boundaries were associated with the box initialisations of the tagging approach. For a small fraction of the precipitation no moisture sources can be determined by the Lagrangian method. This precipitation can be related to small moisture changes along the trajectories (below the threshold of $0.2 \mathrm{~g} \mathrm{~kg}^{-1}$ in $6 \mathrm{~h}$; see Sodemann et al., 2008) or to moisture contained in the air parcel at the beginning of the analysed period (if the trajectory does not leave the model domain). The latter is conceptually similar to the atmospheric tracer of the tagging experiment.

Figure 9 shows the time series of relative contributions of the moisture sources specified in Fig. 4 to the precipitation 
(a)

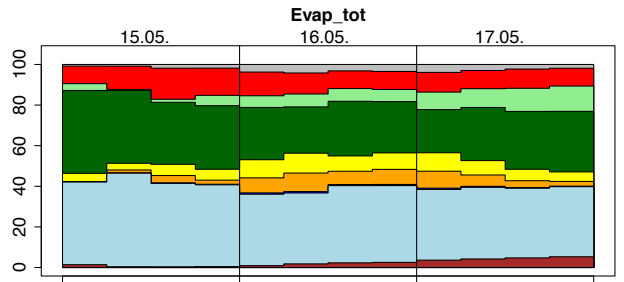

(b)

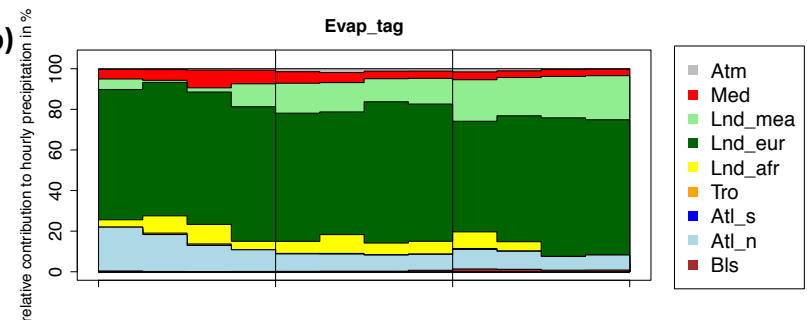

(c)



Figure 9. Relative contribution of the different moisture sources to the hourly precipitation in the target region in eastern Europe between 00:00 UTC on 15 May and 00:00 UTC on 18 May 2010. Results are shown from (a) the COSMO tagging simulation with Evap_tot parameterisation, (b) the COSMO tagging simulation with Evap_tag parameterisation and (c) the Lagrangian moisture source diagnostics.

in the target region between 00:00 UTC on 15 May and 00:00 UTC on 18 May 2010 from the two different parameterisations of the Eulerian tagging approach and the Lagrangian source diagnostics. Integrated contributions for the whole event are given in Table 1 and shown in Fig. 10. As already discussed in Sect. 4 the Evap_tot parameterisation (tracer evaporation equals the net flux of total moisture) is associated with a high fraction of remote moisture sources, mainly from the North Atlantic and the tropics (Fig. 9a). In contrast, the Evap_tag parameterisation, in which the evaporation is proportional to the gradient of each individual tracer, shows much larger contributions from local sources (Fig. 9b). This is due to the enhanced mixing in the surface layer, which leads to the replacement of humidity from remote sources with locally evaporating vapour. For the case of the May 2010 event analysed here, the Evap_tot results indicate two main moisture sources, the western European land mass and the North Atlantic, as discussed in Sect. 4. With the Evap_tag parameterisation the contribution of European land evapotranspiration is considerably higher, with $65 \%$ for the Lnd_eur and $14 \%$ for the Lnd_mea tracer (Fig. 10, Table 1). On the other hand, contributions from the North At-

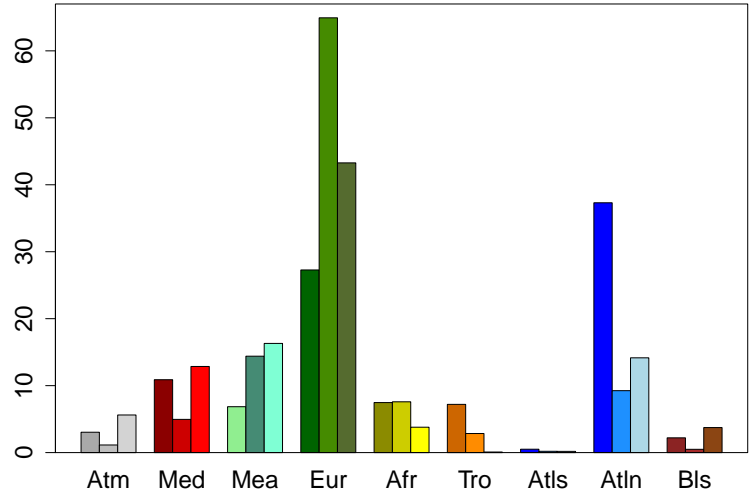

Figure 10. Relative contribution of the different moisture sources to the precipitation in the target region between 00:00 UTC on 15 May and 00:00 UTC on 18 May 2010 (in \%). Three bars are shown for each moisture source, the left one representing the COSMO tagging simulation with parameterisation Evap_tot, the middle one the COSMO tagging simulation with parameterisation Evap_tag and the right one the Lagrangian diagnostics.

lantic are greatly reduced (only $9 \%$ from Atl_n). The results from the Lagrangian diagnostics (Fig. 9c), which are based on specific humidity variations along trajectories, are mostly intermediate between the two tagging realisations. The fraction of western European moisture is in between the values indicated by the two Eulerian estimates, with up to $60 \%$ at the first day and between 40 and $50 \%$ on 16 and 17 May. For the first day the fraction of Mediterranean moisture is higher compared to the Eulerian results, as is the fraction of the Bls source at the last day of the precipitation event. The tropical and African land moisture contributions indicated by the Lagrangian diagnostics are small, but detectable. The temporal variability of the moisture sources contributing to the precipitation event is relatively small, but mostly consistent between the different methods, which indicate larger contributions from the Mediterranean in the beginning of the event and more moisture from easterly sources (Lnd_mea, Bls) towards the end (see again Fig. 9).

Given that the Lagrangian diagnostics is methodologically and conceptually different from the Eulerian tagging approach, the similarity of the results is remarkable. Both methods show that the North Atlantic and evapotranspiration from the European land surface are the dominating sources for the heavy-precipitation event. The contributions of these two main sources obtained from the Lagrangian diagnostics are in between the estimates from the two tagging realisations (see again Table 1). Nevertheless, the relative importance of the different moisture sources varies between the methods, and especially the differences between the two tagging approaches are relatively large. In summary this shows that, on the one hand, a large uncertainty is associated with the parameterisation of surface evaporation in the Eulerian approach but that, on the other hand, qualitatively similar 


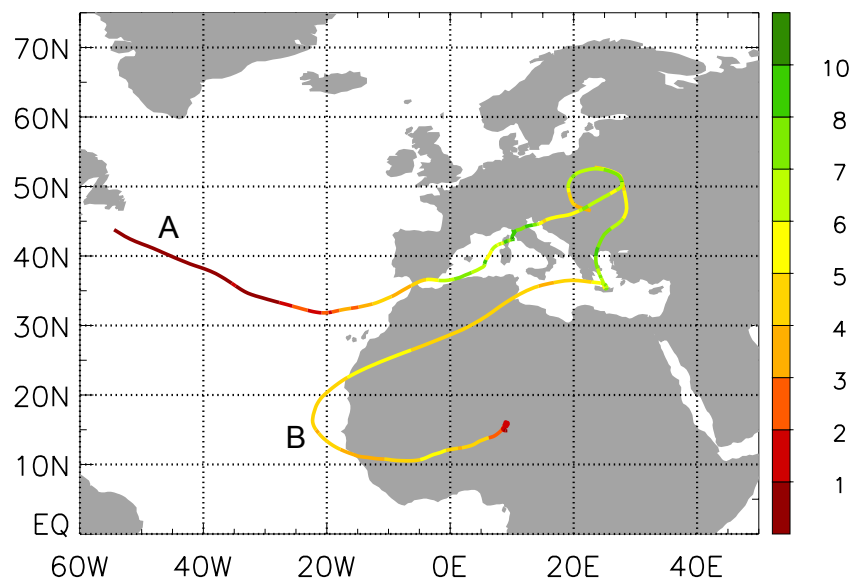

Figure 11. Exemplary 10-day backward trajectories from eastern Europe started at 12:00 UTC on 16 May 2010 with a trajectory path ending over the Atlantic (A) and over Africa (B). Colours indicate the specific humidity along the trajectories in $\mathrm{g} \mathrm{kg}^{-1}$. Trajectory A starts from $22.75^{\circ} \mathrm{E}, 46.54^{\circ} \mathrm{N}$ and a height of $3626 \mathrm{~m}$. Trajectory $\mathrm{B}$ starts from $23.39^{\circ} \mathrm{E}, 52.75^{\circ} \mathrm{N}$ and the same height.

conclusions can be drawn from the Lagrangian and Eulerian diagnostics. Further comparison studies are necessary to investigate the generality of these results. Note that the results obtained from the different moisture source diagnostics provide important information on the source-sink relationship of atmospheric humidity, but this cannot be directly interpreted to quantify the role of moisture from a particular region. For instance, through strongly non-linear feedback processes in the atmospheric hydrological cycle, a relatively small contribution from a particular source region can have a very important effect on the resulting precipitation. Likewise, the technique does not indicate how precipitation would change if evaporation in a particular region were enhanced or reduced.

\section{$7 \quad$ Analysis of exemplary trajectories}

In order to compare the two approaches in more detail, we study the moisture changes along two exemplary trajectories shown in Fig. 11. Note that these trajectories are not selected because of their representativeness for larger trajectory clusters. Trajectory A follows a zonal path from the North Atlantic to eastern Europe; the path of trajectory B is more meridional from North Africa over the Mediterranean. In addition to changes in total specific humidity (which are used to diagnose surface evaporation in the Lagrangian approach), the different Eulerian moisture tracers have been tracked along these trajectories. Evaluating variations in these tracers during moisture uptakes and losses can help to validate some of the assumptions made in the Lagrangian diagnostics. The tracers from the COSMO simulation with the Evap_tot parameterisation are used for this analysis.
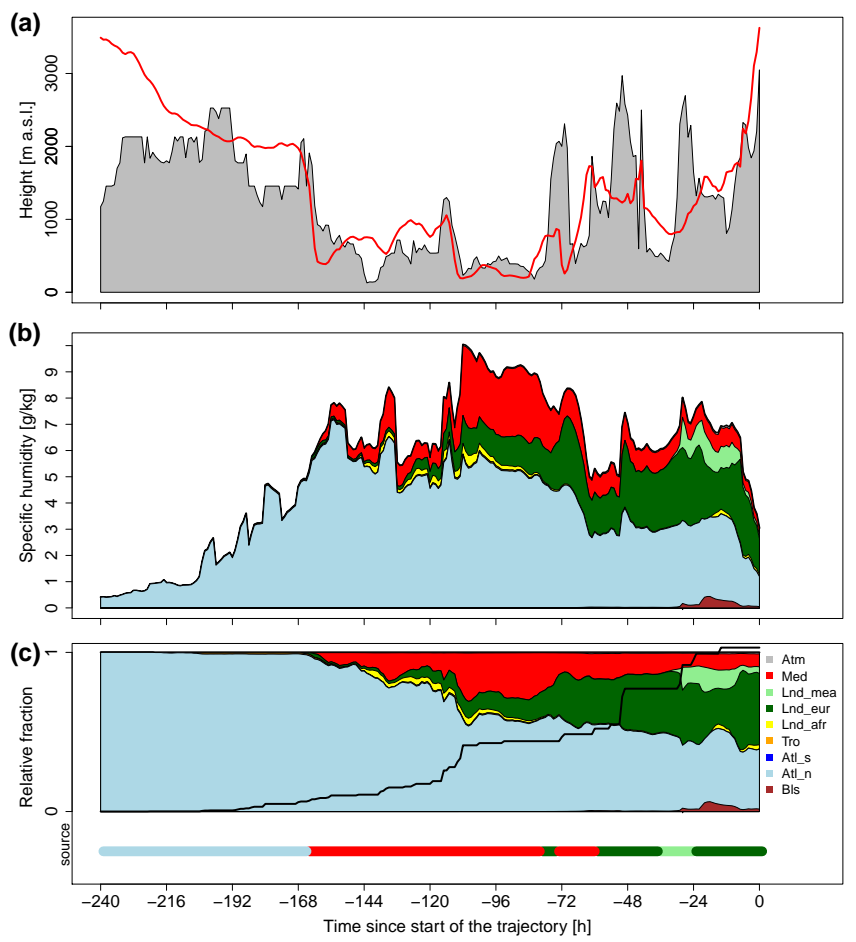

Figure 12. Moisture source analysis along a 10-day trajectory moving from the Atlantic to eastern Europe (trajectory A in Fig. 11). (a) Trajectory height (red, in $\mathrm{m}$ ) and scaled boundary layer height (grey shading, in $\mathrm{m}$ ). (b) Specific humidity (in $\mathrm{g} \mathrm{kg}^{-1}$ ) along the trajectory decomposed into the different moisture sources of the tagging experiment (see Fig. 4). (c) Relative contributions of the tracers to the specific humidity (shading) and accounted fraction of the Lagrangian diagnostics (black line). The coloured thick line in the lower part indicates the source areas corresponding to the actual position of the air parcel.

Figure 12 shows a synopsis of data relevant for diagnosing the moisture transport along the trajectory path. Hour 0 corresponds to the start of the trajectory over eastern Europe and hour -240 to the end of the backward trajectory over the North Atlantic. In Fig. 12a the trajectory altitude is shown together with the height of the ABL (scaled by a factor of 1.5; see Sect. 2.2). Figure 12b shows the specific humidity along the trajectory, which is decomposed into the different moisture sources specified for the tagging experiment. In Fig. 12c the relative contributions of these tracers are displayed, which facilitates the detection of changes in the relative tracer composition. The black line indicates the accounted moisture fraction from the Lagrangian analysis, i.e. the fraction of the specific humidity that can be related to previous moisture uptakes (see Sodemann et al., 2008). Finally, the coloured thick line in the lower part shows the moisture source areas corresponding to the actual trajectory position. If the Lagrangian and the Eulerian tagging methods are in perfect agreement, a moisture uptake by an air parcel located in the ABL will only consist of the tracer from the 

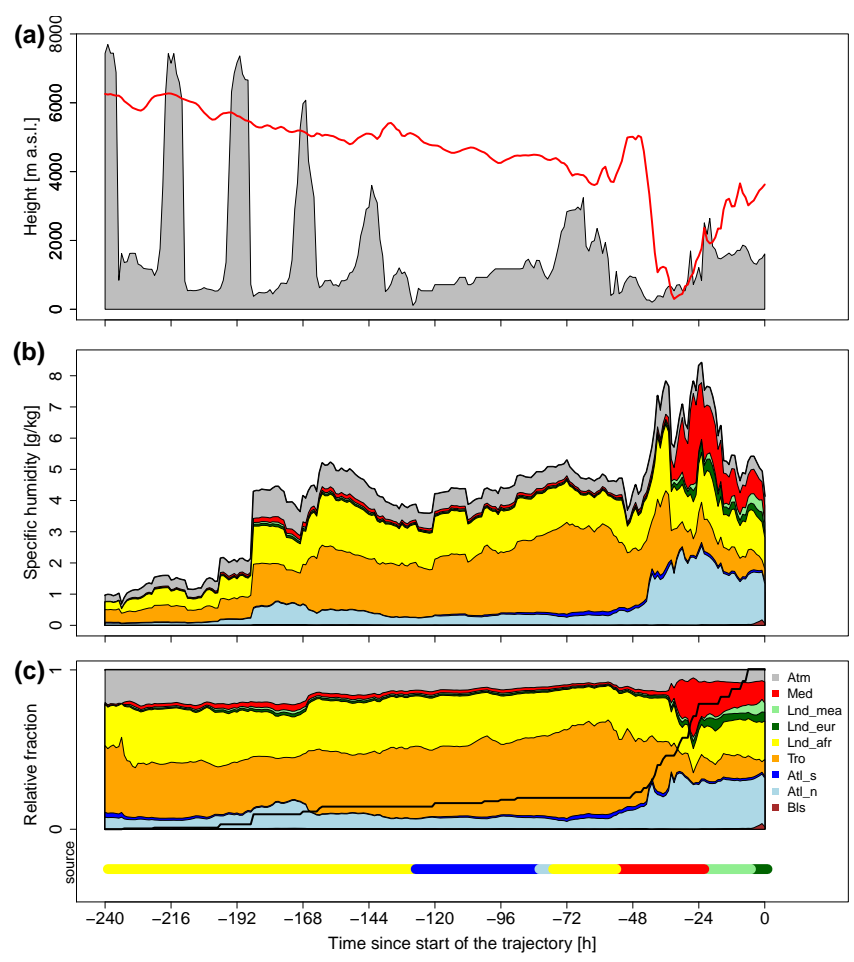

Figure 13. Same as Fig. 12, but for a trajectory moving from Africa towards eastern Europe (trajectory B in Fig. 11).

corresponding source area. Moisture losses due to precipitation will be equally distributed among the tracers.

For the example trajectory A this concept appears to work well at most times. Between hours -240 and -168 the trajectory is located over the North Atlantic and all moisture uptakes are associated with the corresponding Atl_n tracer. Later, the trajectory moves over the Mediterranean and the European continent. Large positive changes in specific humidity (around hours $-114,-60$ and -36 ) occur when the air parcel is located in the ABL and mainly consist of moisture from the underlying source. By design, the accounted fraction of the Lagrangian diagnostics increases during these moisture uptakes. The uptake at hour -114 contributes less to the final precipitation compared to the uptakes at around hour -60 and -36 because of interim moisture losses due to precipitation. When moisture is lost around hours -60 and -12 the relative fractions of the tracers stay mostly unchanged, which also indicates consistency between the Eulerian and the Lagrangian diagnostics. However, there are also features that are not consistent in both approaches. The increase of Lnd_eur and Lnd_afr moisture between hours -144 and -80 and the contribution of Bls moisture in the last $24 \mathrm{~h}$ cannot be explained by the Lagrangian method, in which all moisture uptakes are attributed to the underlying source. These moisture contributions are connected to horizontal or vertical mixing of moisture, which is not captured

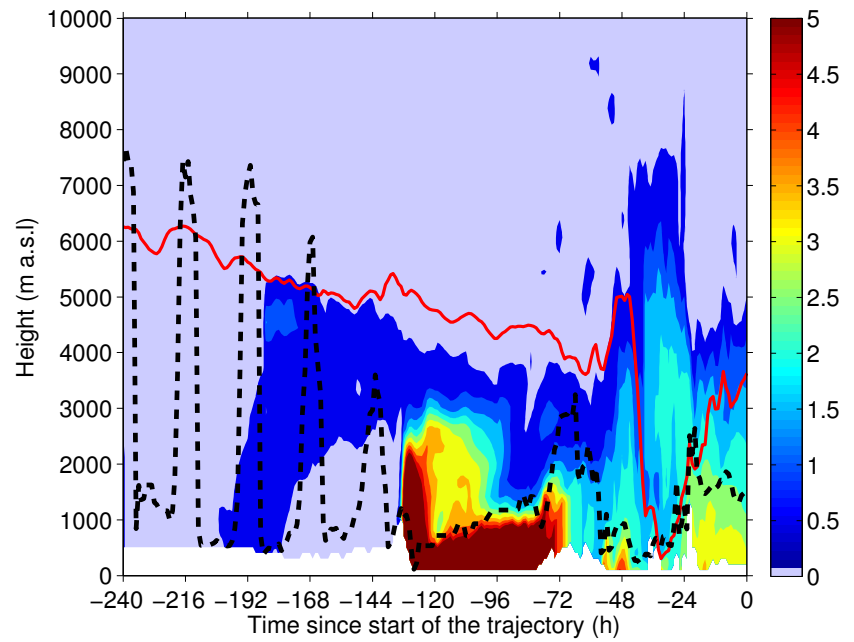

Figure 14. Vertical profile of the tagged specific humidity (in $\mathrm{g} \mathrm{kg}^{-1}$ ) of the sum of both Atlantic tracers along trajectory B in Fig. 11. The height of the air parcel is shown by the red solid line; the scaled boundary layer height is indicated by the black dashed line.

in the trajectory calculations and not parameterised in the Lagrangian diagnostics.

Trajectory B takes a path from sub-Saharan western Africa near $10^{\circ} \mathrm{N}$ over the North Atlantic, the Sahara and the Mediterranean towards eastern Europe (Fig. 11). Over Africa the trajectory is located at high altitudes and contains a mixture of moisture from tropical, African land and unaccounted sources (Fig. 13). The strong daily cycle of the continental boundary layer is visible in Fig. 13a. During the day the ABL strongly expands in association with a humidity increase in the air parcel. These moisture uptakes are composed of a mixture of different sources (Tro, Lnd_afr and Atl), which cannot be captured by the Lagrangian diagnostics. The most important moisture uptakes for the precipitation in the target region occur during the last $48 \mathrm{~h}$. Most of the uptakes in the $\mathrm{ABL}$ are associated with the underlying sources, the Mediterranean and the European land mass. The increase of North Atlantic moisture between hours -48 and -24 is again not diagnosed by the Lagrangian method. To illustrate the cause of this increase, Fig. 14 shows a vertical profile of the sum of the Atlantic tracers (Atl_s and Atl_n) along the analysed trajectory. When the trajectory is located over the North Atlantic between hours -130 and -80 (Fig. 13), Fig. 14 shows high specific humidity values of Atlantic origin in the boundary layer. Between hours -130 and -96 high moisture values are found also above the ABL, which indicates that the ABL scaling factor of 1.5 (see again Sect. 2.2) might be too conservative to capture all this residual moisture. There is no increase of the North Atlantic tracers in the air parcel during this period, as it is located at a high altitude of around $5000 \mathrm{~m}$. When the trajectory descends around hour -40 , also North Atlantic moisture is present over the Mediterranean 
and the European continent. This moisture mixes with the drier descending air, which leads to the increase of Atlantic moisture in the last $48 \mathrm{~h}$ in Fig. 13.

This detailed analysis indicates that the concept of the Lagrangian approach to link moisture uptakes in the ABL to evaporation from the underlying surface is mostly consistent with the more advanced Eulerian tagging approach, which comprises an explicit representation of evaporation and precipitation. Nevertheless, some inconsistencies occur due to vertical and horizontal mixing of moisture from different sources that is not captured by the Lagrangian approach. This particularly affects moisture uptakes far above the ABL. In this case, the assumption of a vertically well-mixed atmosphere and a direct connection between a moisture uptake and evaporation from the underlying surface may not be valid. This is consistent with the recent findings of Goessling and Reick (2013).

\section{Conclusions}

In this study the moisture sources for the flood event in eastern Europe in May 2010 have been analysed with an Eulerian tagging approach implemented in the COSMO limitedarea model and a Lagrangian diagnostics based on backward trajectory calculations. These diagnostics, though varying in the accentuation of different moisture contributions, consistently indicate two main sources contributing to the heavyprecipitation event: moisture from the North Atlantic and local evapotranspiration from the European land surface. The land evapotranspiration is fuelled from previous precipitation, and the remote sources of this precipitation cannot be determined with the techniques applied here. Moisture from the Mediterranean Sea with a fraction of about $10 \%$ is not a major contributor to the event, in contrast to what one might guess from the cyclone track over the Mediterranean towards eastern Europe. A further interesting moisture source indicated by the tagging method is connected to large-scale transport of tropical moisture from western Africa, which might be associated with an African easterly wave present over western Africa about 5 days before the precipitation in eastern Europe. Up to $15 \%$ of the precipitation can be attributed to this tropical source.

The inter-comparison of the tagging approach with different parameterisation schemes for tracer evaporation (Evap_tot, based on the net flux of total moisture, and Evap_tag, based on vertical gradients of individual tracers) and the Lagrangian diagnostics yields overall similar results for the moisture sources of the precipitation event in eastern Europe, while there are some differences in the relative importance of the different source regions. The Evap_tot approach emphasises remote sources, while in the Evap_tag approach such remote moisture is more easily replaced along the path to the location of the event, enhancing contributions from local sources. More detailed investigations of the surface layer mixing and a more advanced parameterisation scheme accounting for two-way humidity fluxes are required to reduce the uncertainty associated with the parameterisation of surface evaporation and further clarify the conceptual differences between the two tagging approaches. The results of the Lagrangian diagnostics are similar to the $\mathrm{Eu}-$ lerian results, with the fraction of remote versus local moisture sources lying in between the two realisations of the tagging technique. An in-depth analysis of the changes of tagged and total humidity along exemplary trajectories supports the linkage of moisture uptakes within the atmospheric boundary layer to evaporation from the underlying surface. However, more complex mechanisms accounted for in the tagging approach, like mixing above the ABL, are not captured by the Lagrangian diagnostics. Overall, this comparison indicates that the two complementary approaches are both very useful for studies of the atmospheric water cycle. For detailed case studies, the Eulerian tagging approach is clearly more comprehensive, although finding the most suitable prespecification of the considered moisture sources can be difficult in some cases. For climatological studies, the Lagrangian approach is a computationally inexpensive alternative that can be run for large areas and long time periods. In the future, Eulerian tagging simulations on long timescales with regional models and high spatial resolution might become possible as well, building upon the experience from the onemonth tagging simulation by Sodemann and Stohl (2013).

Acknowledgements. We are grateful to the EU project ENSEMBLES and the European Climate Assessment \& Dataset team (http://www.ecad.eu) for providing the E-OBS data set as well as to MeteoSwiss for giving access to ECMWF analysis data. We thank Michael Sprenger (ETH Zurich) for help in producing the satellite image. The constructive comments from H. F. Goessling, B. Rutherford and the editor, T. Dunkerton, have helped us to improve the manuscript.

Edited by: T. J. Dunkerton

\section{References}

Appenzeller, C., Bader, S., Duding, O., Eckert, P., Frei, F., Germann, U., Hächler, P., Keuerleber-Burk, D. K., Liniger, M., Rotach, M., Schubiger, F., Walser, A., and Zbinden, P.: Starkniederschlagsereignis August 2005, Arbeitsbericht Meteoschweiz Nr. 211, iSSN: 1422-1381, 2006.

Baldauf, M., Seifert, A., Förstner, J., Majewski, D., and Raschendorfer, M.: Operational convective-scale numerical weather prediction with the COSMO Model: description and sensitivities, Mon. Weather Rev., 139, 3887-3905, doi:10.1175/MWR-D-1005013.1, 2011.

Bosilovich, M. G. and Schubert, S. D.: Water vapor tracers as diagnostics of the regional hydrological cycle, J. Hydrometeorol., 3, 149-165, 2002.

Bissolli, P., Friedrich, K., Rapp, J., and Ziese, M.: Flooding in eastern central Europe in May 2010 - reasons, evolution and climato- 
logical assessment, Weather, 66, 147-153, doi:10.1002/wea.759, 2011.

Bott, A.: A positive definite advection scheme obtained by nonlinear renormalization of the advective fluxes, Mon. Weather Rev., 117, 1006-1015, 1989.

Dirmeyer, P. A. and Brubaker, K. S.: Contrasting evaporative moisture sources during the drought of 1988 and the flood of 1993, J. Geophys. Res., 104, 19383-19397, doi:10.1029/1999JD900222, 1999.

Doms, G. and Schättler, U.: A description of the nonhydrostatic regional model LM. Part I: Dynamics and numerics, Deutscher Wetterdienst, Offenbach, Germany, 2002.

Doms, G., Förstner, J., Heise, E., Herzog, H. J., Raschendorfer, M., Schrodin, R., Reinhardt, T., and Vogel, G.: A description of the nonhydrostatic regional model LM. Part II: Physical parameterization, Deutscher Wetterdienst, Offenbach, Germany, 2005.

Gimeno, L., Drumond, A., Nieto, R., Trigo, R. M., and Stohl, A.: On the origin of continental precipitation, Geophys. Res. Lett., 37, L13804, doi:10.1029/2010GL043712, 2010.

Gimeno, L., Stohl, A., Trigo, R. M., Dominguez, F., Yoshimura, K., Yu, K. L., Drumond, A., Durán-Quesada, A. M., and Nieto, R.: Oceanic and terrestrial sources of continental precipitation, Rev. Geophys., 50, RG4003, doi:10.1029/2012RG000389, 2012.

Goessling, H. F.: Continental moisture recycling and evaporationprecipitation coupling: water as passive tracer and as active component, PhD Thesis, University of Hamburg, Germany, 2013.

Goessling, H. F. and Reick, C. H.: On the "well-mixed" assumption and numerical 2-D tracing of atmospheric moisture, Atmos. Chem. Phys., 13, 5567-5585, doi:10.5194/acp-13-55672013, 2013.

Haylock, M. R., Hofstra, N., Klein Tank, A. M. G., Klok, E. J., Jones, P. D., and New, M.: A European daily high-resolution gridded dataset of surface temperature and precipitation, J. Geophys. Res., 113, D20119, doi:10.1029/2008JD010201, 2008.

Hohenegger, C., Walser, L., Langhans, W., and Schar, C.: Cloudresolving ensemble simulations of the August 2005 Alpine flood, Q. J. Roy. Meteor. Soc., 134, 889-904, doi:10.1002/qj.252, 2008.

James, P., Stohl, A., Spichtinger, N., Eckhardt, S., and Forster, C.: Climatological aspects of the extreme European rainfall of $\mathrm{Au}-$ gust 2002 and a trajectory method for estimating the associated evaporative source regions, Nat. Hazards Earth Syst. Sci., 4, 733746, doi:10.5194/nhess-4-733-2004, 2004.

Joussaume, S., Sadourny, R., and Vignal, C.: Origin of precipitating water in a numerical simulation of July climate, Ocean-Air Interact., 1, 43-56, 1986.

Keil, C., Volkert, H., and Majewski, D.: The Oder flood in July 1997: transport routes of precipitable water diagnosed with an operational forecast model, Geophys. Res. Lett., 26, 235-238, doi:10.1029/1998GL900274, 1999.

Knippertz, P., Wernli, H., and Gläser, G.: A global climatology of tropical moisture exports, J. Climate, 26, 3031-3045, doi:10.1175/JCLI-D-12-00401.1, 2013.

Koster, R., Jouzel, J., Souzzo, R., Russell, G., Broecker, W., Rind, D., and Eagleson, P.: Global sources of local precipitation as determined by the NASA/GISS GCM, Geophys. Res. Lett., 13, 121-124, doi:10.1029/GL013i002p00121, 1986.

Pfahl, S., Wernli, H., and Yoshimura, K.: The isotopic composition of precipitation from a winter storm - a case study with the limited-area model $\mathrm{COSMO}_{\text {iso }}$, Atmos. Chem. Phys., 12, 16291648, doi:10.5194/acp-12-1629-2012, 2012.

Sodemann, H. and Stohl, A.: Moisture origin and meridional transport in atmospheric rivers, and their association with multiple cyclones, Mon. Weather Rev., 141, 2850-2868, doi:10.1175/MWR-D-12-00256.1, 2013.

Sodemann, H. and Zubler, E.: Seasonal and inter-annual variability of the moisture sources for Alpine precipitation during 19952002, Int. J. Climatol., 30, 947-961, doi:10.1002/joc.1932, 2010.

Sodemann, H., Schwierz, C., and Wernli, H.: Interannual variability of Greenland winter precipitation sources: Lagrangian moisture diagnostic and North Atlantic Oscillation influence, J. Geophys. Res., 113, D03107, doi:10.1029/2007JD008503, 2008.

Sodemann, H., Wernli, H., and Schwierz, C.: Sources of water vapour contributing to the Elbe flood in August 2002 - a tagging study in a mesoscale model, Q. J. Roy. Meteor. Soc., 135 , 205-223, doi:10.1002/qj.374, 2009.

Steppeler, J., Doms, G., Schättler U., Bitzer H. W., Gassmann A., Damrath U., and Gregoric G.: Meso-gamma scale forecasts using the nonhydrostatic model LM, Meteorol. Atmos. Phys., 82, 7596, doi:10.1007/s00703-001-0592-9, 2003.

Stohl, A. and James, P.: A Lagrangian analysis of the atmospheric branch of the global water cycle. Part I: Method description, validation, and demonstration for the August 2002 flooding in central Europe, J. Hydrometeorol., 5, 656-678, 2004.

Tiedtke, M.: A comprehensive mass flux scheme for cumulus parameterization in large-scale models, Mon. Weather Rev., 117, 1779-1800, 1989.

Ulbrich, U., Brücher, T., Fink, A. H., Leckebusch, G. C., Krüger, A., and Pinto, J. G.: The central European floods of August 2002: Part 1 - Rainfall periods and flood development, Weather, 58, 371-377, doi:10.1256/wea.61.03A, 2003a.

Ulbrich, U., Brücher, T., Fink, A. H., Leckebusch, G. C., Krüger, A., and Pinto, J. G.: The central European floods of August 2002: Part 2 - Synoptic causes and considerations with respect to climatic change, Weather, 58, 371-377, doi:10.1256/wea.61.03B, 2003b.

Wicker, L. and Skamarock, W.: A time-splitting scheme for the elastic equations incorporating second-order Runge-Kutta time differencing, Mon. Weather Rev., 126, 1992-1999, 1998.

Winschall, A.: Evaporative moisture sources for heavy precipitation events, Dissertation No. 20923, ETH Zuerich, Switzerland, available at: http://e-collection.library.ethz.ch/view/eth:6776, 2013.

Winschall, A., Pfahl, S., Sodemann, H., and Wernli, H.: Impact of North Atlantic evaporation hot spots on southern Alpine heavy precipitation events, Q. J. Roy. Meteor. Soc., 138, 1245-1258, doi:10.1002/qj.987, 2012.

van Bebber, W. J.: Die Zugstrassen der barometrischen Minima nach den Bahnenkarten der Deutschen Seewarte von 1875-1890, Meteorol. Z., 8, 361-366, 1891.

Zängl, G.: To what extent does increased model resolution improve simulated precipitation fields? A case study of two north-Alpine heavy-rainfall events, Meteorol. Z., 16, 571-580, doi:10.1127/0941-2948/2007/0237, 2007a.

Zängl, G.: Interaction between dynamics and cloud microphysics in orographic precipitation enhancement: a high-resolution modeling study of two north-Alpine heavy precipitation events, Mon. Weather Rev., 78, 279-294, doi:10.1175/MWR3445.1, 2007b. 